\title{
Pancreatic pseudocyst with fistula to the common bile duct resolved by combined biliary and pancreatic stenting - a case report and literature review
}

\author{
Jaber A Al Ali MD¹, Henry Chung MD¹, Peter L Munk MD², Michael F Byrne MD¹
}

JA Al Ali, H Chung, PL Munk, MF Byrne. Pancreatic pseudocyst with fistula to the common bile duct resolved by combined biliary and pancreatic stenting - a case report and literature review. Can J Gastroenterol 2009;23(8):557-559.

Pancreatic pseudocysts develop in $10 \%$ to $20 \%$ of patients with chronic pancreatitis, and can cause a variety of complications such as infection, bleeding or development of fistulae. However, fistulous communication with the common bile duct is very rare. The present report describes an unusual case of a patient with a large, symptomatic pancreatic pseudocyst with a fistula to the common bile duct that was treated successfully by combined biliary and pancreatic stenting.

Key Words: Fistula; Pancreatitis; Pseudocyst; Stenting
Un pseudokyste pancréatique accompagné d'une fistule vers le canal cholédoque, résolu par une endoprothèse biliaire et pancréatique combinée : Rapport de cas et analyse bibliographique

De $10 \%$ à $20 \%$ des patients atteints d'une pancréatite chronique acquièrent un pseudokyste pancréatique qui peut causer diverses complications telles qu'une infection, une hémorragie ou l'apparition de fistules. Cependant, la communication fistulaire avec le canal cholédoque est très rare. Le présent rapport décrit le cas inhabituel d'un patient ayant un gros pseudokyste pancréatique symptomatique, accompagné d'une fistule vers le canal cholédoque traitée avec succès par une endoprothèse biliaire et pancréatique combinée.
Dancreatic pseudocysts (PPs) are present in approximately $10 \%$ to $20 \%$ of patients with chronic pancreatitis, and most commonly occur in alcoholic chronic pancreatitis. Abdominal pain is the most common symptom, with nausea, vomiting, palpable abdominal mass, bleeding and jaundice being less common findings. Complications include bleeding, common bile duct (CBD) obstruction, duodenal obstruction and external-internal pancreatic fistulae. These fistulae are found in 5\% to $41 \%$ of cases. Treatment generally consists of percutaneous, endoscopic or surgical drainage for individuals with symptoms, complications or enlarging pseudocysts. We diagnosed a 42-year-old man who had a PP with a fistulous communication to the CBD. This has not been described previously, other than in a small number of case reports.

\section{CASE PRESENTATION}

A 42-year-old Caucasian man with a history of deep vein thrombosis, heparin-induced thrombocytopenia, chronic pancreatitis secondary to alcohol abuse and a PP drained surgically five years previously, presented to Vancouver General Hospital, Vancouver, British Columbia. The patient had a two-week history of progressive jaundice, mild-to-moderate dull right upper quadrant pain and a $6 \mathrm{~kg}$ to $8 \mathrm{~kg}$ weight loss over a one-year period. The physical examination revealed a deeply jaundiced and mildly febrile patient $\left(37.8^{\circ} \mathrm{C}\right)$. In addition, his right upper quadrant was tender, with mild hepatomegaly. The initial laboratory investigation revealed a hemoglobin level of $100 \mathrm{~g} / \mathrm{L}$, a mean corpuscular volume of $116 \mathrm{fL}$, gammaglutamyl transferase $387 \mathrm{U} / \mathrm{L}$, alkaline phosphatase $1192 \mathrm{U} / \mathrm{L}$, alanine aminotransferase $120 \mathrm{U} / \mathrm{L}$, aspartate aminotransferase $206 \mathrm{U} / \mathrm{L}$, international normalized ratio 1.27 , albumin $24 \mathrm{~g} / \mathrm{L}$ and direct bilirubin $180 \mathrm{mg} / \mathrm{L}$. Radiological examination, including abdominal ultrasound and computed tomography scan, showed a relatively thin-walled, cystic mass in the region of the pancreatic head measuring $9.6 \mathrm{~cm} \times 8.5 \mathrm{~cm} \times 8.4 \mathrm{~cm}$, causing mild pancreatic duct $(4 \mathrm{~mm}$ to $5 \mathrm{~mm}$ ) and CBD dilation $(10 \mathrm{~mm}$ ). In addition, there were multiple punctate pancreatic calcifications (Figure 1). Subsequently, the patient underwent endoscopic retrograde cholangiopancreatography (ERCP) that revealed a long, distal CBD stricture and a large pseudocyst in the head of the pancreas, filling via a fistulous communication with the CBD at the middle of the stricture (Figure 2). A $10 \mathrm{Fr}$, $10 \mathrm{~cm}$ Cotton-Leung stent (Cook Medical, USA) was placed in the $\mathrm{CBD}$, and a $7 \mathrm{Fr}, 7 \mathrm{~cm}$ double-pigtail stent was placed via the transpapillary route across the fistula into the pseudocyst (Figure 3). The patient was started on antibiotics and discharged home a few days later - after his symptoms dramatically improved and liver enzymes normalized. He remained pain-free without further hospitalization. A follow-up computed tomography scan of his abdomen two months later showed a dramatic resolution of the pseudocyst (Figure 4). The pigtail stent was removed during ERCP two months after the

${ }^{1}$ Department of Medicine, Division of Gastroenterology; ${ }^{2}$ Division of Radiology, Vancouver General Hospital, University of British Columbia,

Vancouver, British Columbia

Correspondence: Dr Michael F Byrne, Division of Gastroenterology, University of British Columbia, 5135-2775 Laurel Street, Vancouver,

British Columbia V5Z 1M9. Telephone 604-875-5640, fax 604-875-5447, e-mail michael.byrne@vch.ca

Received for publication January 26, 2009. Accepted January 30, 2009 


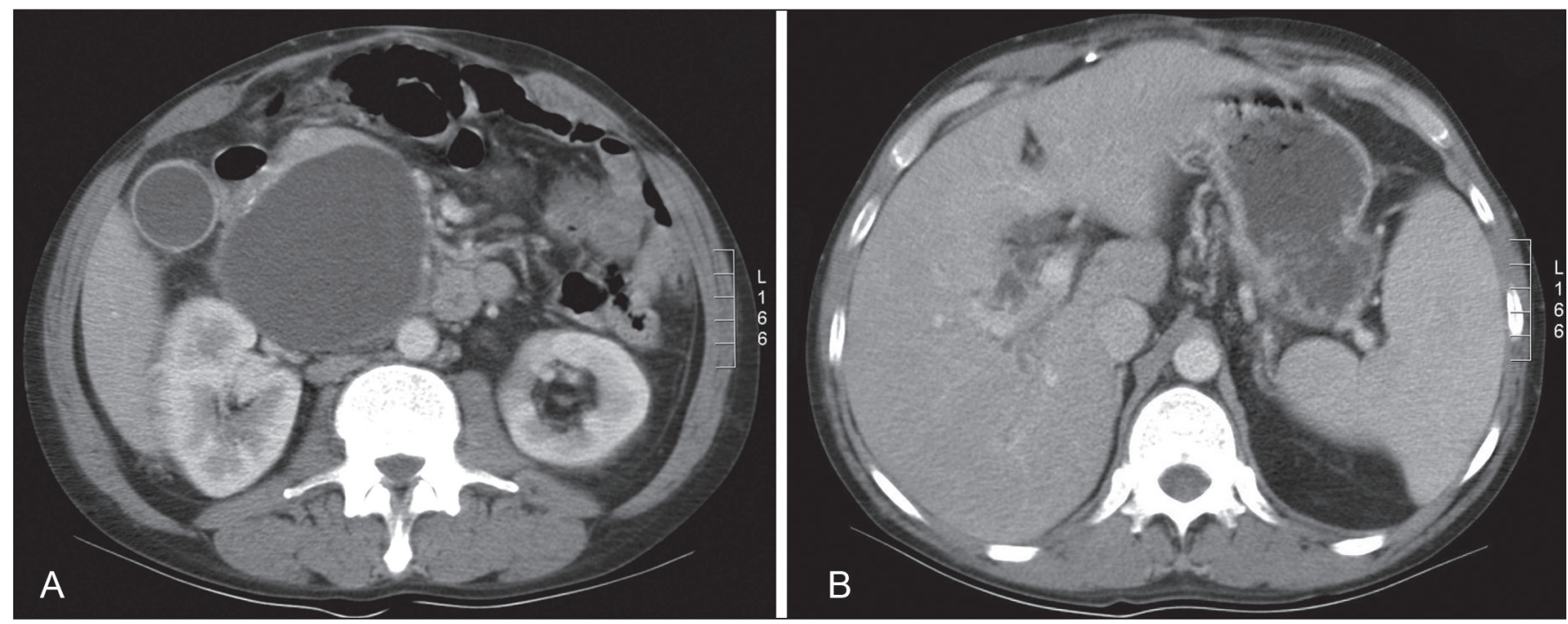

Figure 1) A Contrast-enhanced computed tomography scan of the upper abdomen. A relatively thin-walled cystic mass is identified in the region of the pancreatic head measuring $9.6 \mathrm{~cm} \times 8.5 \mathrm{~cm} \times 8.4 \mathrm{~cm}$ in size. Multiple punctate pancreatic calcifications are seen, consistent with a history of pancreatitis. B The cyst indents the common bile duct anteriorly, with intrahepatic biliary dilation

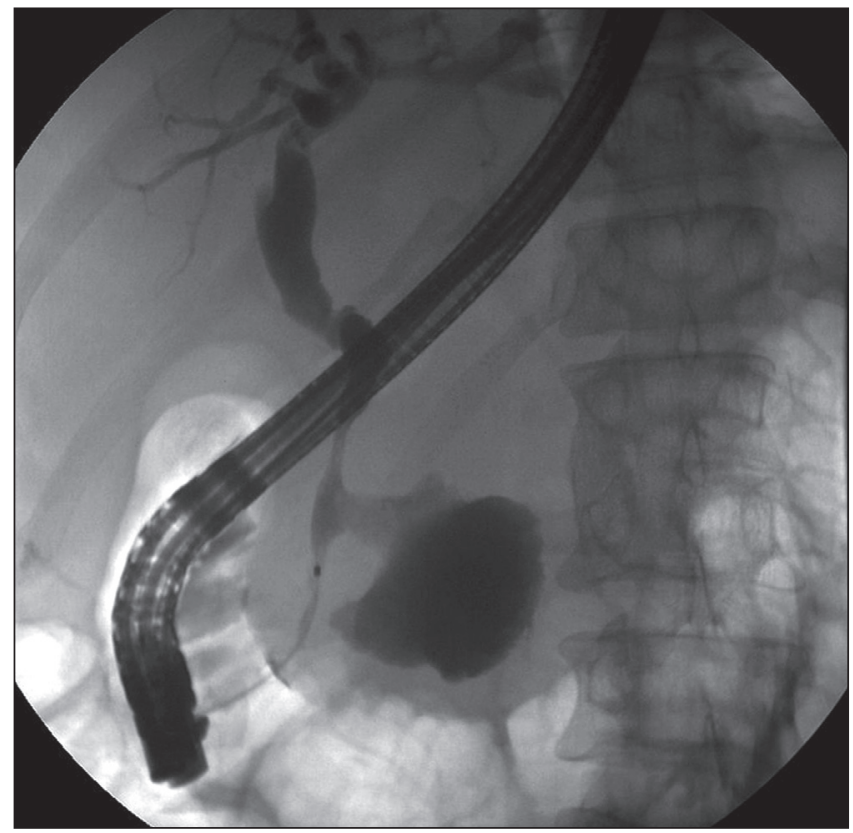

Figure 2) Image from an endoscopic retrograde cholangiopancreatography following injection of contrast into the biliary system. A biliary stricture is seen, with a patulous communication between the common bile duct and the pseudocyst

initial presentation and the biliary stent was exchanged in view of the persisting biliary stricture. ERCP performed after one further month revealed no evidence of residual fistulous communication between the CBD and the previous pseudocyst. The patient continued to do well and was scheduled for further stenting of his biliary stricture. The bile duct stricture was presumed secondary to chronic pancreatitis and to compression from the previous pseudocyst. It was unclear at this stage whether he required longer-term biliary stenting or perhaps surgery, or whether this stricture was mainly the result of a relatively inflammatory process.

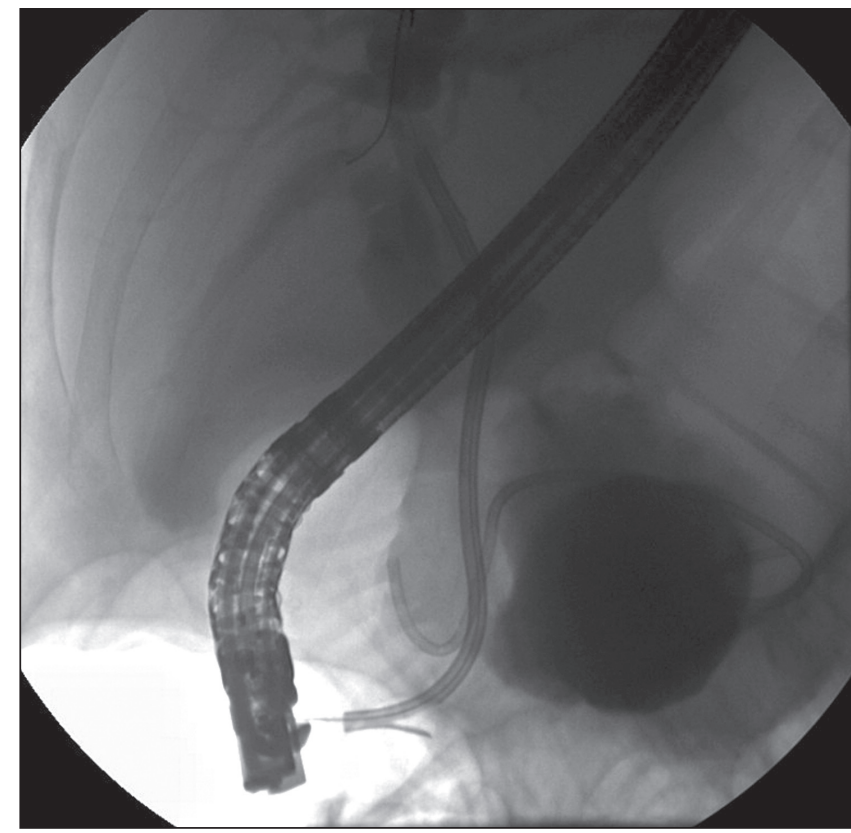

Figure 3) A Cotton-Leung stent (Cook Medical, USA) placed in the common bile duct across the site of the communication. A second double-pigtail stent extends from within the cavity across the bile duct and into the duodenum

\section{DISCUSSION}

PPs occur in approximately $10 \%$ to $20 \%$ of patients with chronic pancreatitis, and are most commonly seen in alcoholic chronic pancreatitis (1). PPs are persistent, peripancreatic, enzyme-rich fluid collections with a clearly defined fibrous wall but lacking a true epithelial lining (1). Pseudocysts are typically caused by disruption of the pancreatic duct with extravasation of pancreatic enzymes. Such disruption can be caused either by an acute event (trauma or stone passage) or repeated attacks of pancreatitis. Approximately 30\% of acute pseudocysts resolve spontaneously; however, thick-walled chronic pseudocysts can often persist and enlarge. Both acute and chronic pseudocysts 
can cause serious complications such as sepsis, obstruction, hemorrhage, pancreatic ascites and, rarely, fistula formation to other viscera. The most common organs to which pseudocysts can fistulize are the stomach, duodenum, colon and, less commonly, the esophagus (2). Fistulas to the biliary tract are distinctly rare. In fact, to our knowledge, there have been only 16 cases of PPs with fistula to the CBD reported in the literature (3-15) (Table 1). Among these 16 cases, most were in men. Alcoholic chronic pancreatitis was the most common etiology, with abdominal pain being the most common clinical presentation. Ten of 16 cases were treated surgically, three patients were treated with percutaneous external drainage of the pseudocyst and one patient was observed. Only two cases were successfully treated endoscopically by placing one stent in the biliary tract and another across the fistula $(14,15)$. Fistulous communication of a PP to the CBD is uncommon. We have demonstrated that it can be successfully managed endoscopically. It was believed that biliary stenting alone would not have been adequate because the pseudocyst was quite large, as was the size of the fistulous communication with the CBD.

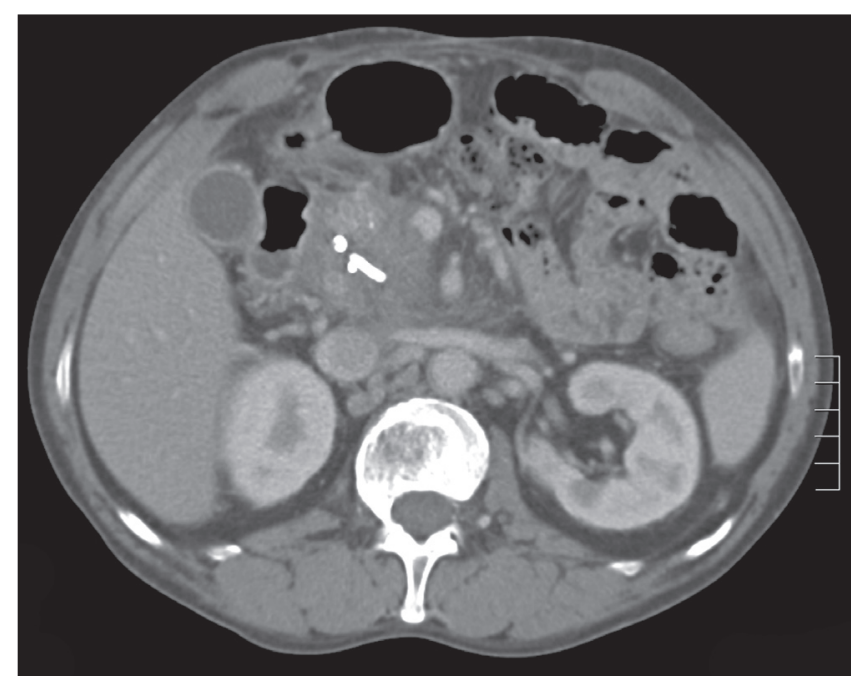

Figure 4) Follow-up contrast-enhanced computed tomography scan of the abdomen showing a significant decrease in the size of the pseudocyst with the two stents in position

\section{TABLE 1}

Summary of case reports in the literature

\begin{tabular}{|c|c|c|c|c|}
\hline $\begin{array}{l}\text { Author } \\
\text { (reference) }\end{array}$ & $\begin{array}{l}\text { Patient } \\
\text { sex/age, years }\end{array}$ & $\begin{array}{l}\text { Type and etiology } \\
\text { of pancreatitis }\end{array}$ & Presentation & Treatment \\
\hline Dalton et al (3) & Male/61 & Chronic alcoholic & Abdominal pain & Cystoduodenostomy \\
\hline Sankaran and Walt (4) & Unknown & Alcoholic & Unknown & Unknown \\
\hline Grace and Jordan (5) & Unknown & Unknown & Unknown & Choledochoduodenostomy \\
\hline Ro and Yoon (6) & Male/66 & Chronic & Abdominal pain & Cystoduodenostomy \\
\hline Gadacz et al (7) & Male/59 & Chronic alcoholic & Abdominal pain & Pancreaticoduodenectomy \\
\hline Gadacz et al (7) & Male/40 & Chronic alcoholic & Abdominal pain & Cholecystostomy, external drainage \\
\hline Skellenger et al (8) & Male/47 & Acute alcoholic & Abdominal pain & External drainage \\
\hline Ellenbogen et al (9) & Male/54 & Chronic alcoholic & Abdominal pain & Cystojejunostomy \\
\hline DeVanna et al (10) & Male/2 & Acute & Dehydration, upper respiratory infection & Observation \\
\hline Hauptmann et al (11) & Male/53 & Chronic alcoholic & Abdominal pain & External drainage \\
\hline Bresler et al (12) & Male/66 & Chronic alcoholic & Abdominal pain & T-tube, choledochotomy \\
\hline Raimondo et al (13) & Female/69 & Chronic alcoholic & Abdominal pain & Pancreaticojejunostomy \\
\hline Boulanger et al (14) & Male/52 & Alcoholic & Abdominal pain & Endoscopic internal drainage \\
\hline Carrere et al (15) & Male/74 & Chronic alcoholic & Abdominal pain & Endoscopic internal drainage \\
\hline Carrere et al (15) & Male/67 & Acute & Abdominal pain & Cystojejunostomy, hepaticojejunostomy, cholecystectomy \\
\hline Carrere et al (15) & Male/65 & Acute & Abdominal pain & Cholecystectomy, biliary and pancreatic bypass \\
\hline
\end{tabular}

\section{REFERENCES}

1. Grace PA, Williamson RC. Modern management of pancreatic pseudocysts. Br J Surg 1993;80:573-81.

2. Clements JL Jr, Bradley EL III, Eaton SB Jr. Spontaneous internal drainage of pancreatic pseudocysts. Am J Roentgenol 1976;126:98-991.

3. Dalton WE, Lee HM, Williams GM, Hume DM. Pancreatic pseudocyst causing hemobilia and massive gastrointestinal hemorrhage. Am J Surg 1970;120:106-7.

4. Sankaran S, Walt AJ. The natural and unnatural history of pancreatic pseudocysts. Br J Surg 1975;62:37-44.

5. Grace RR, Jordan PH Jr. Unresolved problems of pancreatic pseudocysts. Ann Surg 1976;184:16-21.

6. Ro JO, Yoon BH. Pancreatic pseudocyst as a cause of gastrointestinal bleeding and hemobilia. A case report. Am J Gastroenterol 1976;66:287-91.

7. Gadacz TR, Lillemoe K, Zinner M, Merrill W. Common bile duct complications of pancreatitis evaluation and treatment. Surgery 1983;93:235-42.

8. Skellenger ME, Patterson D, Foley NT, Jordan PH Jr. Cholestasis due to compression of the common bile duct by pancreatic pseudocysts. Am J Surg 1983;145:343-8.

9. Ellenbogen KA, Cameron JL, Cocco AE, Gayler BW, Hutcheon DF. Fistulous communication of a pseudocyst with the common bile

duct: Demonstration by endoscopic retrograde cholangiopancreatography. Johns Hopkins Med J 1981;149:110-1.

10. DeVanna T, Dunne MG, Haney PJ. Fistulous communication of pseudocyst to the common bile duct: A complication of pancreatitis. Pediatr Radiol 1983;13:344-5.

11. Hauptmann EM, Wojtowycz M, Reichelderfer M, McDermott JC, Crummy AB. Pancreatic pseudocyst with fistula to the common bile duct: Radiological diagnosis and management. Gastrointest Radiol 1992;17:151-3.

12. Bresler L, Vidrequin A, Poussot D, et al. Fistulous communication of a pancreatic pseudocyst with the common bile duct: Demonstration by operative cholangiogram. Am J Gastroenterol 1989;84:835-6.

13. Raimondo M, Ashby AM, York EA, Derfus GA, Farnell MB, Clain JE. Pancreatic pseudocyst with fistula to the common bile duct presenting with gastrointestinal bleeding Dig Dis Sci 1998;43:2622-6.

14. Boulanger S, Volpe CM, Ullah A, Lindfield V, Doerr R. Pancreatic pseudocyst with biliary fistula: Treatment with endoscopic internal drainage. South Med J 2001;94:347-9.

15. Carrere C, Heyries L, Barthet M, Bernard JP, Grimaud JC, Sahel J. Biliopancreatic fistulas complicating pancreatic pseudocysts: A report of three cases demonstrated by endoscopic retrograde cholangiopancreatography. Endoscopy 2001;33:91-4. 


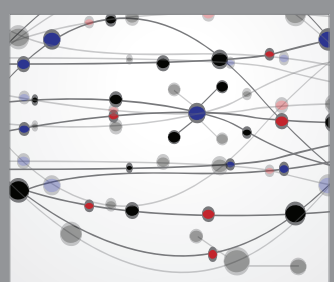

The Scientific World Journal
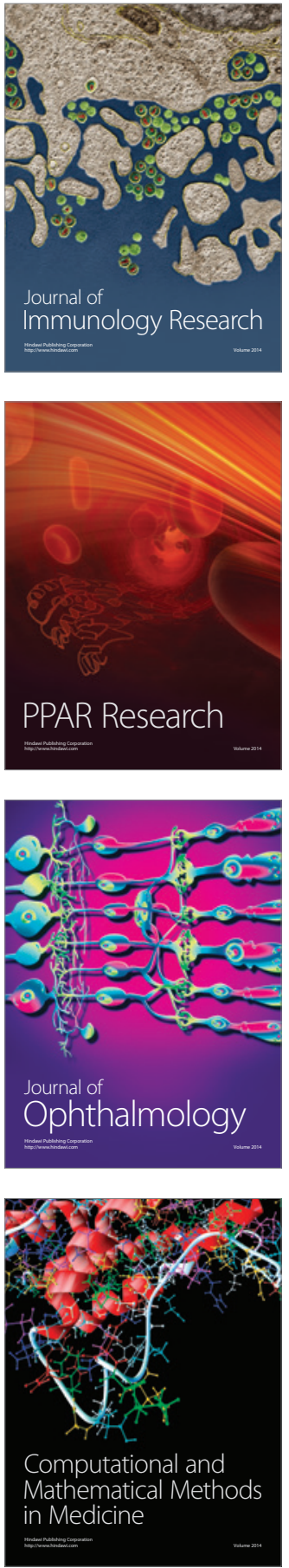

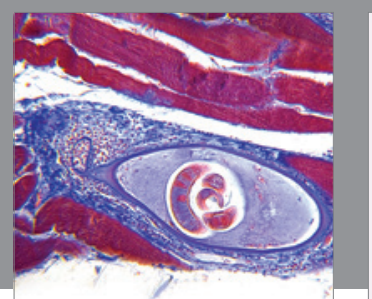

Gastroenterology Research and Practice

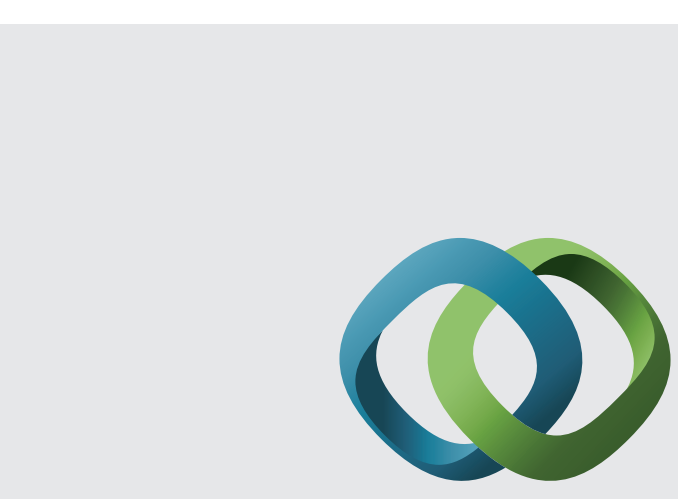

\section{Hindawi}

Submit your manuscripts at

http://www.hindawi.com
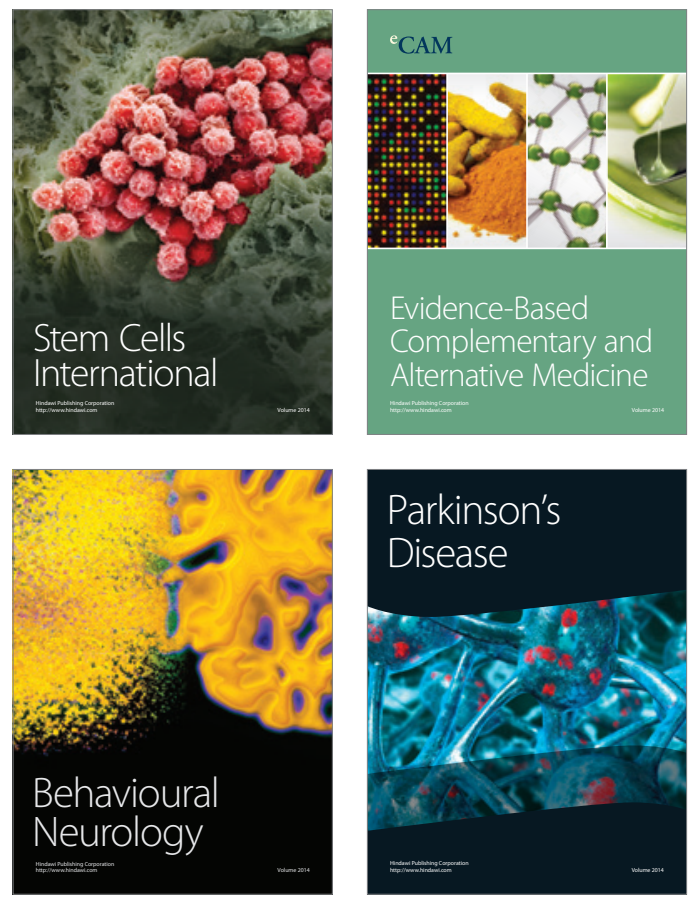
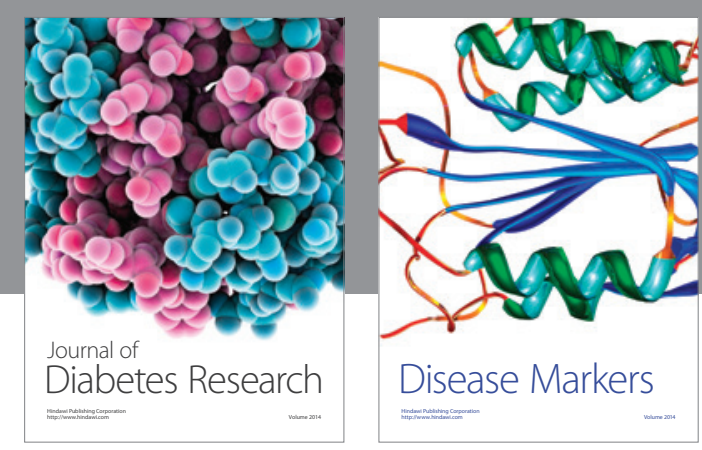

Disease Markers
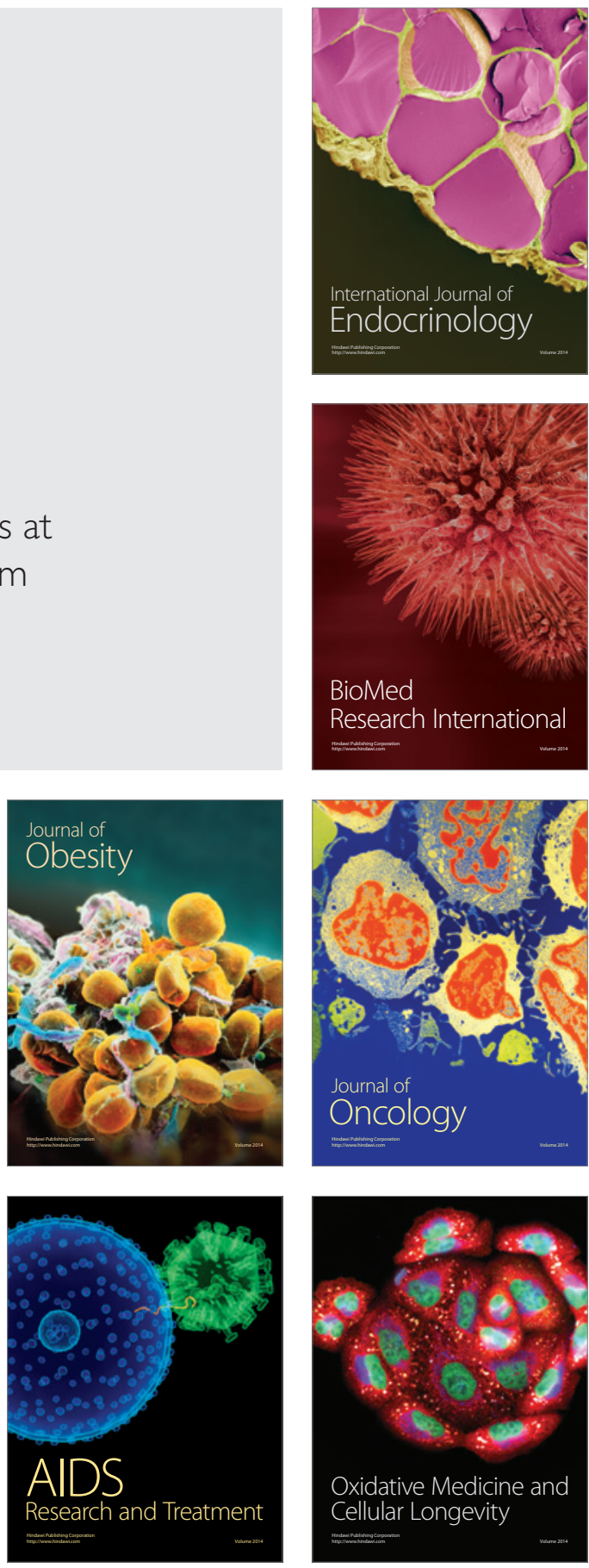